\title{
Chimeric Antigen Receptor-modified T cells targeting EphA2 for the immunotherapy of paediatric bone tumours
}

\author{
Kenneth $\mathrm{Hsu}^{1}$ - Shiloh Middlemiss ${ }^{1} \cdot$ Federica Saletta ${ }^{1} \cdot$ Stephen Gottschalk $\mathbb{D}^{2} \cdot$ Geoffrey B. McCowage $^{3}$. \\ Belinda Kramer (iD ${ }^{1}$
}

Received: 5 May 2020 / Revised: 14 August 2020 / Accepted: 21 August 2020 / Published online: 1 September 2020

(c) The Author(s), under exclusive licence to Springer Nature America, Inc. 2020

\begin{abstract}
Chimeric Antigen Receptor (CAR) T-cell therapy, as an approved treatment option for patients with B cell malignancies, demonstrates that genetic modification of autologous immune cells is an effective anti-cancer regimen. Erythropoietinproducing Hepatocellular receptor tyrosine kinase class A2 (EphA2) is a tumour associated antigen expressed on a range of sarcomas, including paediatric osteosarcoma (OS) and Ewing sarcoma (ES). We tested human EphA2 directed CAR T cells for their capacity to target and kill human OS and ES tumour cells using in vitro and in vivo assays, demonstrating that EphA2 CAR T cells have potent anti-tumour efficacy in vitro and can eliminate established OS and ES tumours in vivo in a dose and delivery route dependent manner. Next, in an aggressive metastatic OS model we demonstrated that systemically infused EphA2 CAR T cells can traffic to and eradicate tumour deposits in murine livers and lungs. These results support further pre-clinical evaluation of EphA2 CAR T cells to inform the design of early phase clinical trial protocols to test the feasibility and safety of this immune cell therapy in paediatric bone sarcoma patients.
\end{abstract}

\section{Introduction}

Despite substantial improvements in the survival of children diagnosed with cancer over recent decades, children with recurrent or metastatic bone tumours such as osteosarcoma (OS) or Ewing sarcoma (ES) face a poor prognosis. The recent establishment of Chimeric Antigen Receptor (CAR) based T-cell immunotherapy as an effective treatment for B cell malignancies [1] demonstrates that gene modification of immune cells to target tumour associated antigens (TAA) is a powerful method of disease control. It is well documented

Supplementary information The online version of this article (https:// doi.org/10.1038/s41417-020-00221-4) contains supplementary material, which is available to authorised users.

Belinda Kramer

Belinda.Kramer@health.nsw.gov.au

1 Children's Cancer Research Unit, Kid's Research, The Children's Hospital at Westmead, Westmead, NSW 2145, Australia

2 Department of Bone Marrow Transplant and Cellular Therapy, St. Jude Children's Research Hospital, Memphis, TN, USA

3 Children's Cancer Centre, The Children's Hospital at Westmead, Westmead, NSW 2145, Australia that $\mathrm{T}$ cells have the capacity to infiltrate bone tumours [2-4], however, the significance of their presence has long been a subject of conjecture: some [4], but not all studies [3] report a relationship between T-cell presence within tumours and treatment outcomes. Studies attempting to generate autologous cytotoxic $\mathrm{T}$ cells from bone tumour patients have also reported variable results, demonstrating the difficulties in developing endogenous tumour infiltrating lymphocytes (TIL) as a therapeutic option [5, 6]. Adoptive transfer of gene modified, CAR bearing $\mathrm{T}$ cells offers an alternative strategy that bypasses the need for identification and expansion of endogenous TIL, with proven efficacy at least in B cell malignancies [1].

By design, CAR T cells are functionally uncoupled from requirements of MHC-mediated antigen presentation and co-stimulatory receptor engagement, and are unaffected by TCR-mediated $\mathrm{T}$ regulatory cell (Treg) suppression that mitigates against their presence within the tumour microenvironment [4]. Successful translation of CAR T-cell therapies into effective treatments for bone tumours requires identification of suitable TAAs, coupled with effective delivery to the tumour. Currently there are a range of TAA's being investigated in both pre-clinical studies and in early phase trials as putative targets for sarcomas. These include Human Epidermal Growth Factor Receptor 2 (HER2) [7, 8], 
the ganglioside antigen GD2 [9], type-I insulin-like growth factor receptor (IGF1R), tyrosine kinase-like orphan receptor 1 (ROR1) [10], Interleukin-13 Receptor $\alpha 2$ (IL13R $\alpha 2$ ) [11] and a range of melanoma TAAs [12]. Our work focuses on the EphA2 protein, which normally acts as a tyrosine kinase receptor for Ephrin signalling during embryonic development [13], with post-development expression largely confined to some epithelial cell layers $[14,15]$. EphA2 overexpression is widely reported across a broad range of cancer types [16, 17], with functional significance for tumour formation and spread, prompting an increasing interest in this protein as a therapeutic target in cancer $[18,19]$. In OS and ES, EphA2 overexpression has been linked to oncogenic signalling [20], the promotion of angiogenesis [21] and tumour aggressiveness [22]. More broadly, in tumours such as colorectal cancer [23], breast cancer [24], pancreatic cancer [25], melanoma [26] and lung cancer [27], EphA2 expression has been associated with tumour proliferative and migratory capacity. EphA2 overexpression in tumours has been shown to have prognostic significance in lung cancer [27, 28], renal cell carcinoma [29], ovarian cancer [30] and brain tumours [31].

We hypothesise that EphA2 is a promising target in both OS and ES due to high levels of expression in tumours, contrasting with low-level expression in normal bone [20, 32]. Moreover, EphA2 expression in malignant tissue is reported to reveal targetable peptide epitopes that are unavailable for binding in normal epithelial tissues [33]. EphA2 protein has been investigated as an immunotherapy target in solid tumours using antibody-drug conjugates [34$36]$, as a source of immunogenic peptides [37, 38] and as a ligand of agonists to promote EphA2 degradation to enhance T-cell activity against the tumour [39]. In preclinical studies testing EphA2 CAR T-cell efficacy, antitumor cytotoxicity has been demonstrated against oesophageal squamous cell carcinoma cells in vitro [40], in both in vitro and in vivo models of non-small-cell lung cancer [41] and glioma and medulloblastoma, dependent on route of delivery [42-44]. Also in glioma, where EphA2 is being utilised in the development of tumour imaging diagnostics [45], early phase clinical trials testing EphA2 CAR T cell safety and efficacy are registered as completed (NCT02575261) or on-going (NCT03423992). In this study, we first determine the applicability of EphA2 CAR $\mathrm{T}$ cells in targeting paediatric bone sarcomas, with consideration of the extent to which EphA2 expression may lead to on-target but off-tumour effects in normal tissues. We report on the use of a lentiviral $(\mathrm{LV})$ vector to generate EphA2 CAR T cells that specifically target and kill EphA2positive $\left(\mathrm{EphA}^{+}\right)$OS and ES cell lines in vitro, and using in vivo subcutaneous OS and ES mouse models demonstrate that EphA2 CAR T-cell administration to animals with established tumours can result in complete tumour regression, with extended survival in a dose and delivery route-dependent manner. In addition, these CAR T cells can traffic to, and eradicate metastatic deposits of human OS cells in the livers and lungs of mice when delivered systemically.

\section{Materials and methods}

\section{Immunohistochemistry analysis of EphA2 expression of tumour samples and normal tissues}

EphA2 protein expression was analysed by immunohistochemical (IHC) staining of formalin-fixed paraffin embedded (FFPE) tissues derived from a cohort of paediatric sarcoma biopsies, assembled in tissue microarray (TMA) [46], from in house derived and commercially available normal tissue TMAs (BioSB, Santa Barbara) and tissues from the experimental in vivo models described below. Staining was performed using a BOND-RX automatic immunostainer (Leica Biosystem) according to standard protocol. Briefly, samples were sectioned at $4 \mu \mathrm{m}$ and slide deparaffinization was performed with Bond Dewax solution (AR9222, Bond) followed by rehydration and heatmediated epitope retrieval (AR9640, Bond). Slides were incubated at room temperature for $1 \mathrm{~h}$ with EphA2 antibody (6997, Cell Signaling) diluted in Primary Antibody Diluent (AR9352, Bond). Staining was visualised using a Polymer Refine Detection kit (DS9800, Bond) and nuclei were counterstained with haematoxylin. The slides were scanned using an Aperio CS2 virtual microscope (Leica Biosystem). Tumours with $\geq 10 \%$ of cells showing EphA2 membrane staining (or a combination of membrane and cytoplasmic staining) of any intensity were considered EphA2-positive $\left(E p h A 2^{+}\right)$. EphA2 staining intensity was also scored on a semi-quantitative scale of 0 to 3 as follows: no staining ( 0 ), weakly positive staining $(1+)$, moderately positive staining $(2+)$ and strongly positive staining (3+).

A humanised EphA2 antibody that binds to the CAR targeted epitope (\#HPAB-0453-CN, Creative Bio-labs) could not be used in this study due to in-compatibility with the immunostainer system. Since antigen recognition can vary between antibody reagents, analysis of paediatric sarcoma biopsies using this antibody would be of particular relevance in identifying patients with CAR targetable EphA2 expression in future clinical trials.

\section{Lentiviral construct and vector production}

A lentiviral transfer construct to drive expression of a 2nd generation EphA2 CAR in gene modified $\mathrm{T}$ cells was constructed using a codon-optimised and custom synthesised (GeneArt, Thermo Fisher Scientific) humanised 
single-chain variable fragment ( $\mathrm{scFv}$ ) specific for EphA2, 4H5 [47], upstream of an IgG1 hinge region and followed by $41 \mathrm{BB}$ and $\mathrm{CD} 3 \zeta$ as endodomains [42, 43]. The CAR sequence was inserted downstream of the human Elongation Factor-1 $\alpha$ (huEF1- $\alpha)$ promoter within a selfinactivating (SIN) lentiviral backbone (kindly provided by Dr S, Ginn, Children's Medical Research Institute, NSW, Australia). A control EphA2 construct ( $\Delta$ EphA2 CAR, $\Delta$ ) retained the same promoter, scFV, hinge and transmembrane configuration, but with sequences for the cytoplasmic signalling domains (41BB and $\mathrm{CD} 3 \zeta$ ) deleted to disable induction of cytotoxic activity upon antigen engagement. Two EphA2 CAR vectors, with their respective $\triangle$ EphA2 CAR controls, were used in the study, containing an additional transmembrane anchored, truncated protein sequence downstream of a $2 \mathrm{~A}$ sequence at the $3^{\prime}$ end of the CAR cassette to facilitate antibody detection of transduced CAR T cells. The first of these expressed truncated CD19 peptide (tCD19) [42] and the second expressed a custom truncated epidermal growth factor receptor (tEGFR) [48]. Lentiviral vector stocks were generated using PEI mediated transfection of 4 plasmids (transfer plasmid, 2 packaging plasmids and VSV-G envelope plasmid) of 293T cells, and collection of vector containing supernatant in LV Max Production medium (Thermo Fisher Scientific). Purification and concentration of vector stocks were undertaken using the KrosFlo KR2i tangential filtration instrument and mPES/ $500 \mathrm{kD}$ column (Repligen). Vector titre was determined using quantitation of functional transduction of SUP-T1 cells and detection of extracellular tCD19 or tEGFR by antibody labelling and flow cytometry, or by q-PCR quantitation of lentiviral backbone sequences in genomic DNA (gDNA) extracted from transduced HT1080 fibrosarcoma cells.

\section{Cell culture}

A panel of human sarcoma cell lines including OS, ES, rhabdomyosarcoma and other soft tissue sarcomas were used for experiments in vitro. SJSA, HOS-143B, HOS, 778, SW872 and SW982 cell lines were kindly provided by A/ Prof Jia Lin Yang (Sarcoma and Nano-oncology Group, Adult Cancer Program, University of New South Wales, Sydney). All other cell lines, including the human cancer cell lines (TF-1 and SUP-T1) and the neuroblastoma cell line SHEP, were purchased from ATCC (Manassas, Virginia, USA) or DSMZ (Braunschweig, Germany). All cell lines used throughout were subjected to Short Tandem Repeat (STR) profiling by CellBank Australia (Westmead, Australia) to confirm identity.

Cell lines were cultured and maintained in filter capped tissue culture flasks (Corning, New York), and maintained in Dulbecco's Modified Eagle's Medium (DMEM) or
RPMI 1640 (Life Technologies) supplemented with 10\% heat-inactivated foetal calf serum (FCS) (Life Technologies), and maintained at $37{ }^{\circ} \mathrm{C}$ with $5 \% \mathrm{CO}_{2}$. Adherent cells were maintained in exponential growth phase by trypsin passaging (Trypsin-EDTA $0.05 \%$, Life Technologies), when required, every 3-4 days. Suspension cells (TF-1 and SUP-T1) were maintained between $0.3-5 \times 10^{5}$ viable cells/ $\mathrm{mL}$ in RPMI 1640 supplemented with $2 \mathrm{ng} / \mathrm{mL}$ GM-CSF (AF300-03, Lonza) and 1\% L-glutamine (Life Technologies).

\section{CAR T-cell production}

Human T cells were obtained and used under approved Human Research Ethics Committee (HREC, Sydney Children's Hospitals Network) approved protocols. T cells were sourced from normal donor Buffy Coats (BC) obtained under a Material Supply Agreement via the Australian Red Cross Lifeblood. Peripheral blood mononuclear cells (PBMC) were isolated by centrifugation using Lymphoprep (7811, Stem Cell Technologies) in accordance with manufacturer's instructions. T cells were enriched using the EasySep human CD3 positive selection kit (Stem Cell Technologies) and cultured in OpTimizer T-cell expansion medium supplemented with immune cell SR (Thermo Fisher Scientific) and Interleukin 7 (IL-7) and Interleukin15 (IL-15) at 10 and $5 \mathrm{ng} / \mathrm{ml}$ respectively (Miltenyi Biotec). $\mathrm{T}$ cells were activated using $\mathrm{T}$ cell TransAct (Miltenyi Biotech) for 1 day prior to transduction with EphA2 and $\Delta$ CAR LV vectors, and further expanded for 8-10 days before being used in vitro or in vivo assays. Cultured and transduced T-cell suspensions were labelled for flow cytometric analysis with antibodies to CD3 in combination with CD19 or EGFR and had an approximate CD4:CD8 ratio of 30:70, with more than 50\% memory (central and effective) $\mathrm{T}$ cells as assessed by flow cytometry using CD45RA and CCR7 as markers.

\section{Flow cytometry}

Adherent tumour cell lines were harvested from flasks using trypsin and washed with FACS Buffer $(0.1 \%$ BSA $\% / 0.1 \%$ sodium azide in PBS) prior to antibody labelling for detection of EphA2 surface expression with PE Mouse IgG2b, $\mathrm{k}$ isotype control or PE anti-human EphA2 (\#400313 and \#356803, Australian Biosearch) for $30 \mathrm{~min}$ at $4{ }^{\circ} \mathrm{C}$ in the dark. The murine cell line NIH3T3 was included as a negative control for EphA2 labelling on adherent cells, and TF-1 cells (grown in suspension) were included as a human cancer negative control, as this line does not express EphA2, unlike the majority of adherent human cancer cell lines surveyed (data not shown). TF-1 cells were taken directly from culture and washed with FACS Buffer prior to 
labelling as described above. After labelling, cell suspensions were washed in FACS buffer and resuspended for analysis using a Guava ${ }^{\circledR}$ easyCyte Flow Cytometer (Merck Millipore). EphA2 positive and negative control cell lines used to determine the gating regions were SHEP and NIH3T3 respectively. Forward and side scatter were used to discriminate live and dead cells. InCyte Software for Guava $^{\circledR}$ easyCyte Systems (Merck Millipore) was used for analysis.

\section{Cytotoxicity assays}

Human EphA2 ${ }^{+}$sarcoma cell lines and murine NIH3T3 cells (negative control) were co-cultured under different effector/target cell (E:T) ratios with nontransduced T cells (T-NT), control $\Delta$ CAR T cells (T- $\Delta$ ) or EphA2- CAR $\mathrm{T}$ cells (T-EphA2) for $\sim 54 \mathrm{~h}$. This time point was determined in preliminary experiments (impedance-based tumour cell killing, below) as that at which cytotoxicity could be detected against both OS and ES cell lines over a range of E:T ratios. At the end of incubation, the plates were washed three times to remove $\mathrm{T}$ cells, and remaining cells were quantified using the CellTiter-Glo 2.0 assay (Promega) according to the manufacturer's instructions. Tumour cell viability was calculated based on luminescence - ( $\mathrm{T}$ cell and tumour cell co-culture $-\mathrm{T}$ cell alone)/untreated cancer cell) $\times 100 \%$.

\section{Impedance-based tumour cell killing assay}

Continuous tumour cell killing was determined and monitored over time using the xCELLigence system (ACEA Biosciences) as a means of determining kinetics of CAR Tcell response to co-cultivation with tumour cell lines. The OS cell line 143B and ES cell line A673 were plated in 16well E-Plates at 3000 and 5000 cells per well cultured for 20-24 h. CAR-T cells were added at E:T ratios of 1:1, 1:5 and 1:25 with nontransduced $\mathrm{T}$ cells (T-NT) or control $\Delta$ CAR T cells $(\mathrm{T}-\Delta)$ at an E:T ratio of 1:1. EphA2- CAR T cells (T-EphA2) and tumour cells were co-cultured for an additional $80-120 \mathrm{~h}$, and cell index values were collected every $15 \mathrm{~min}$. Cell index data were normalised to the time point immediately prior to the addition of $\mathrm{T}$ cells.

\section{Analysis of cytokine production}

Various ratios of EphA2- CAR T cells (T-EphA2), alongside T-NT or control T- $\Delta$ cells, were co-cultured with cell line tumour cells at different E:T ratios for $48 \mathrm{~h}$. Supernatants were then removed and analysed by ELISA for human Interferon- $\gamma$ (IFN- $\gamma, \mathrm{R} \& \mathrm{D}$ systems) and human Interleukin-2 (IL-2, R\&D systems), in accordance to the manufacturer's instructions.

\section{Osteosarcoma and Ewing sarcoma subcutaneous xenograft model}

All animal work was carried out under protocols approved by the Children's Hospital at Westmead (CHW) and Children's Medical Research Institute (CMRI) Animal Ethics Committee. Mice were purchased from the Animal Resources Centre (ARC), Perth, Australia, and randomised on arrival to control or treatment groups To determine the growth kinetics of the OS cell line 143B and ES cell line A673, 6-8-week-old female NOD scid gamma (NSG) mice received initial (Day 0) subcutaneous injections of $5 \times 10^{6}$ tumour cells in $100 \mu \mathrm{L}$ of Matrigel ${ }^{\circledR}$ Basement Matrix HC (\#354248, BioStrategy) and Dulbecco's Modified Eagle Medium (DMEM) (\#1195-065, Life Technologies) containing 1\% penicillin/streptomycin (\#15140-122, Life Technologies) mixed at 1:1 ratio, using $27 \mathrm{G} \times 13 \mathrm{~mm}$ insulin syringes (\#TER00141, Terumo, Medshop). Tumour measurements $\left(\mathrm{mm}^{3}\right)$ were taken three times per week using electronic callipers until tumour volume $($ Volume $=($ Length $\times$ Width $\times$ Height $) / 2)$ reached an endpoint of $1000 \mathrm{~mm}^{3}$, at which point mice were humanely euthanased.

To determine CAR T-cell efficacy against established tumours, NSG mice were first injected subcutaneously with $5 \times 10^{6}$ tumour cells on Day 0. Tumour measurements $\left(\mathrm{mm}^{3}\right)$ were taken thrice weekly, using electronic callipers until the median tumour volume of the cohort reached 100-200 $\mathrm{mm}^{3}$ (measurable tumour) on Day 7 for both models. At this point, mice were treated with either vehicle (PBS), control T- $\Delta$ cells or T-EphA2 CAR T cells. In the ES model, an additional group of animals received T-NT control cells, cultured in parallel with the CAR T cell preparations. Vehicle or $\mathrm{T}$ cell suspensions were administered either directly into the tumour (intratumoural, IT) via two injections into the capsule surrounding the tumour, or intravenously (IV) via the tail vein, in a total volume of $40 \mu \mathrm{L}$ (IT) or $200 \mu \mathrm{L}$ (IV) using $0.5 \mathrm{~mL} 27 \mathrm{G} \times 13 \mathrm{~mm}$ insulin syringes. Mice were monitored for a maximum holding time of 90 days or until experimental endpoints of tumour volume $\geq 1000 \mathrm{~mm}^{3}$ or weight loss $(\mathrm{g}) \geq 10 \%$. Experiment sample sizes were calculated to detect $(80 \%$ power) a minimum one third reduction in tumour size from $1000 \pm 250 \mathrm{~mm}^{3}$ due to treatment, with a probability of Type I error $=0.05$.

\section{Osteosarcoma metastatic model}

6-8-week-old female NSG mice were injected via the tail vein with a suspension of GFP expressing 143B cells $\left(2.5 \times 10^{5}\right)$ at Day 0, a dose of tumour cells which reliably produces $>25$ metastases in the lungs at Day 14 . Seven days after injection, mice were treated with either 

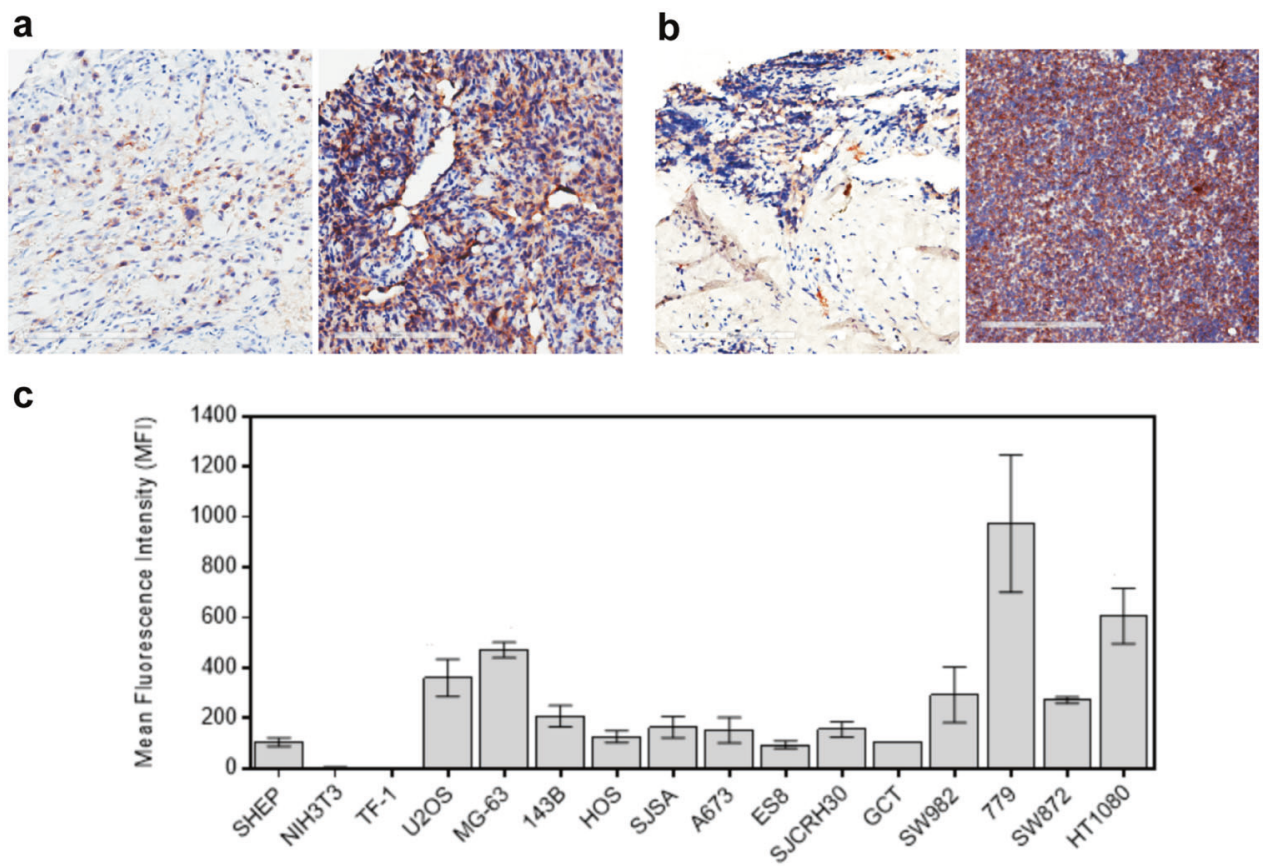

Fig. 1 Expression of tumour-associated antigen target EphA2. a IHC staining of diagnostic OS tumour sections showing weak/Intermediate (left) compared with strong (right) EphA2 staining (brown) against the blue counterstain. b IHC staining of diagnostic ES tumour sections showing weak/intermediate (left) compared with strong (right) EphA2 staining (brown) in against the blue counterstain. Scale bars
$(200 \mu \mathrm{m})$ are shown on the bottom left of each panel. c Flow cytometric analysis of EphA2 expression on adult and paediatric sarcoma cell lines ( $X$ axis). Bars indicate mean \pm SEM of the MFI ( $Y$ axis) for at least three independent experiments. SHEP (neuroblastoma) and TF-1 (erythroleukemia) cell lines were used as positive (SHEP) and negative (TF-1) controls, respectively, for antibody labelling. vehicle (PBS), nontransduced $\mathrm{T}$ cells (T-NT), $\Delta$ CAR $\mathrm{T}$ cells $(\mathrm{T}-\Delta)$ or EphA2 CAR T cells (T-EphA2) which were administered via the tail vein, $5 \times 10^{6} \mathrm{CAR}$ T cells $(200 \mu \mathrm{L})$ using a $0.5 \mathrm{ml} 27 \mathrm{G} \times 13 \mathrm{~mm}$ insulin syringes. On Day 14-16 mice were humanely euthanased and the lungs and liver of each mouse were harvested, and GFP expressing metastatic nodules visible in these organs were counted with the aid of a Nikon SMZ800 dissecting microscope and UV light (BioRad) by technical staff blinded to treatment group. Organs were then fixed in buffered neutral formalin 10\% (Sigma Aldrich, Australia) and embedded in paraffin. FFPE specimen blocks were serially cut into 4- $\mu$ m-thick sections and stained with Haematoxylin and Eosin (H\&E) using standard histological methods. For human IHC antihuman CD3 staining of sections, slides were subjected to low $\mathrm{pH}$ epitope retrieval treatment followed by $1 \mathrm{~h}$ incubation with a 1:200 dilution of the anti-human CD3 (ab5690, Abcam), at room temperature, using the BOND-RX automatic immunostainer protocol described above for EphA2 staining. For further quantitative assessment of liver metastases, H\&E stained slides were scanned using an Aperio CS2 virtual microscope (Leica Biosystems) and the Aperio GENIE Image Analysis Tool (Leica Biosystems) was used to classify tumour regions and determine the percentage of tumour compared with surrounding normal background tissue (data not shown). For analysis of $\mathrm{T}$ cell infiltration into lung and livers of mice, $\mathrm{CD}^{+} \mathrm{T}$ cell density of normal tissues, metastatic deposits and combined tissues, respectively, were scored manually and calculated as an average number of infiltrating $\mathrm{CD}^{+}$cells out of three representative high-power fields. Experiment sample sizes were calculated to detect ( $80 \%$ power) a reduction in metastatic burden of $50 \%$ in treatment groups from a mean of $25 \pm 10$ nodules per organ in control groups, with a probability of Type I error $=0.05$.

\section{Statistical analysis}

Graph-Pad Prism version 6.0 (GraphPad Software, Inc.) was used for all statistical analyses. Log-rank (Mantel-Cox) test was used for survival curve comparisons. Two-tailed Student's $t$ tests and two-way ANOVA tests were used to compare experimental groups where indicated in Figures and Tables. The number of donors used for experiments, the number of independent experiments performed and the number of mice per group are given in Figure legends. $P<$ 0.05 was considered to indicate a statistically significant difference between groups. 


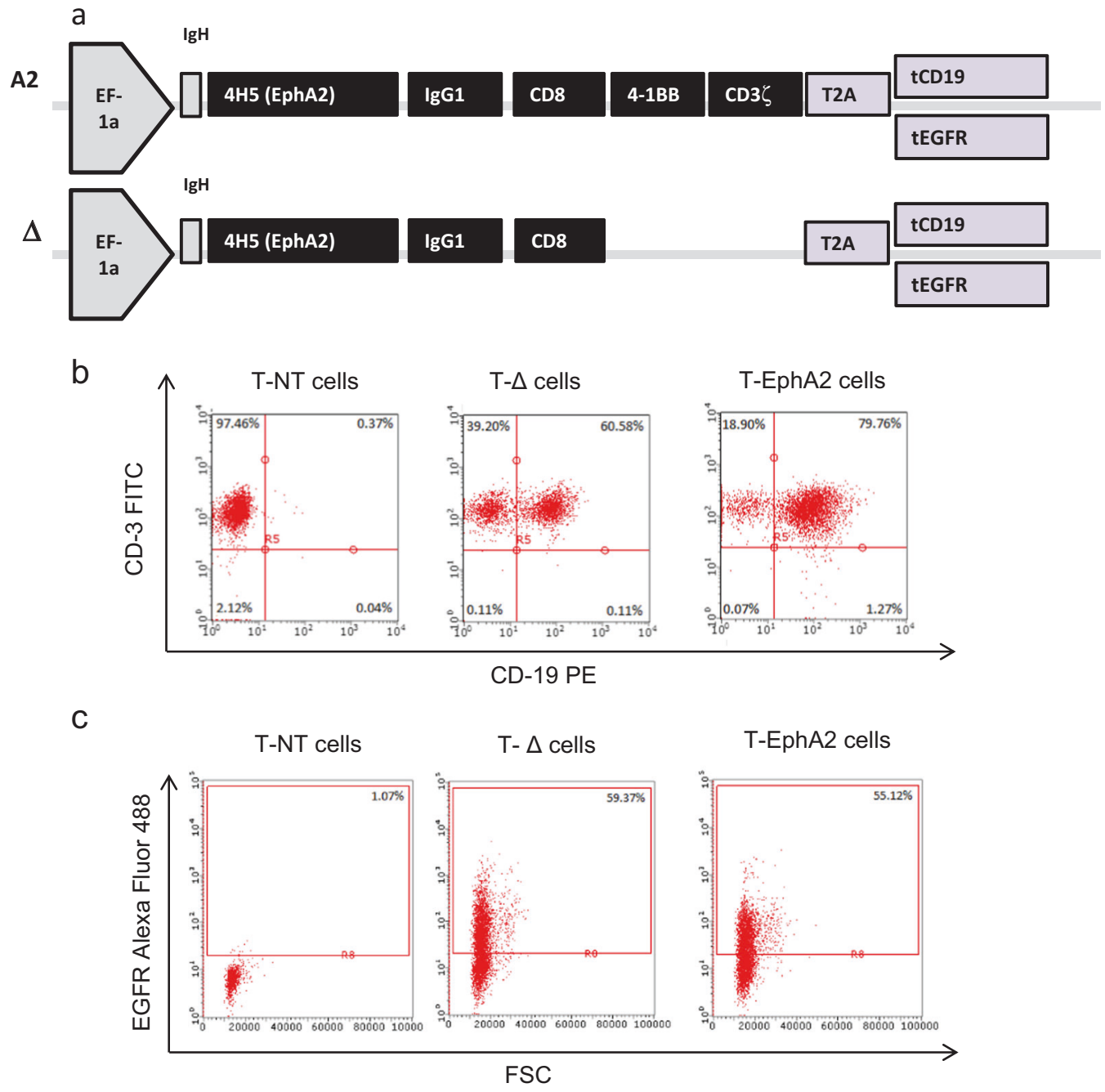

Fig. 2 Vector schematics and LV CAR T-cell transduction efficiencies. a Schematic diagrams showing the EphA2 (T-EphA2) and $\Delta \mathrm{CAR}(\mathrm{T}-\Delta)$ constructs used to generate LV vectors for transduction of T cells. For each A2 construct (containing either the tCD19 OR tEGFR sequence downstream of the CAR sequence) an equivalent control construct was used to generate $\triangle$ CAR T cells in all experiments. b Representative flow cytometry dotplots showing dual CD3

\section{Results}

\section{EphA2 expression in patient tumour samples and normal tissues}

TMA slides containing biopsy cores from 31 OS and 39 ES cases were stained and scored for EphA2 as described above. In the overall patient cohort, $16 / 70$ cases $(23 \%)$ were found to be EphA2-positive. The distribution of weak and moderate/strong EphA2 expression was 10/70 (14.5\%) and $6 / 70$ cases $(8.5 \%)$, respectively. OS cases showed EphA2 expression more commonly $(14 / 31,45 \%)$ than ES cases (2/ $39,5 \%)$. Of the 14 positive OS cases, $9 / 14(64 \%)$ were weakly positive, while $5 / 14(36 \%)$ were moderately to
(FITC, $Y$ axis) and tCD19 (PE, $X$ axis) labelling of control nontransduced (T-NT) T cells, $\Delta$ CAR (T- $\Delta$ ) or EphA2 CAR (T-EphA2) $\mathrm{T}$ cells generated from the same donor. $\mathrm{c}$ Representative flow cytometry dotplots showing tEGFR (Alexa Fluor 488, $X$ axis) against Forward Scatter ( $Y$ axis) labelling of control nontransduced (T-NT) $\mathrm{T}$ cells, $\Delta$ CAR $(\mathrm{T}-\Delta)$ or EphA2 CAR (T-EphA2) T cells generated from the same donor.

strongly EphA2-positive. The two positive ES cases were one each of the weak and moderate/strong category. Examples of IHC membrane staining in OS and ES cases are shown in Fig. 1a, b respectively. There was no significant association between EphA2 expression and disease stage at clinical presentation, biopsy site (primary or metastasis) or whether biopsies were obtained before or after chemotherapy (Supplemental Table 1).

Across the two TMAs containing normal tissues, all tissues tested were negative for EphA2 staining (Supplemental Fig. 1), including brain, skin, skeletal muscle, breast, thyroid, liver, haematopoietic tissues (bone marrow, thymus, lymph node, spleen and tonsil), genitourinary system tissues (adrenal gland, kidney, bladder, testes, prostate, 

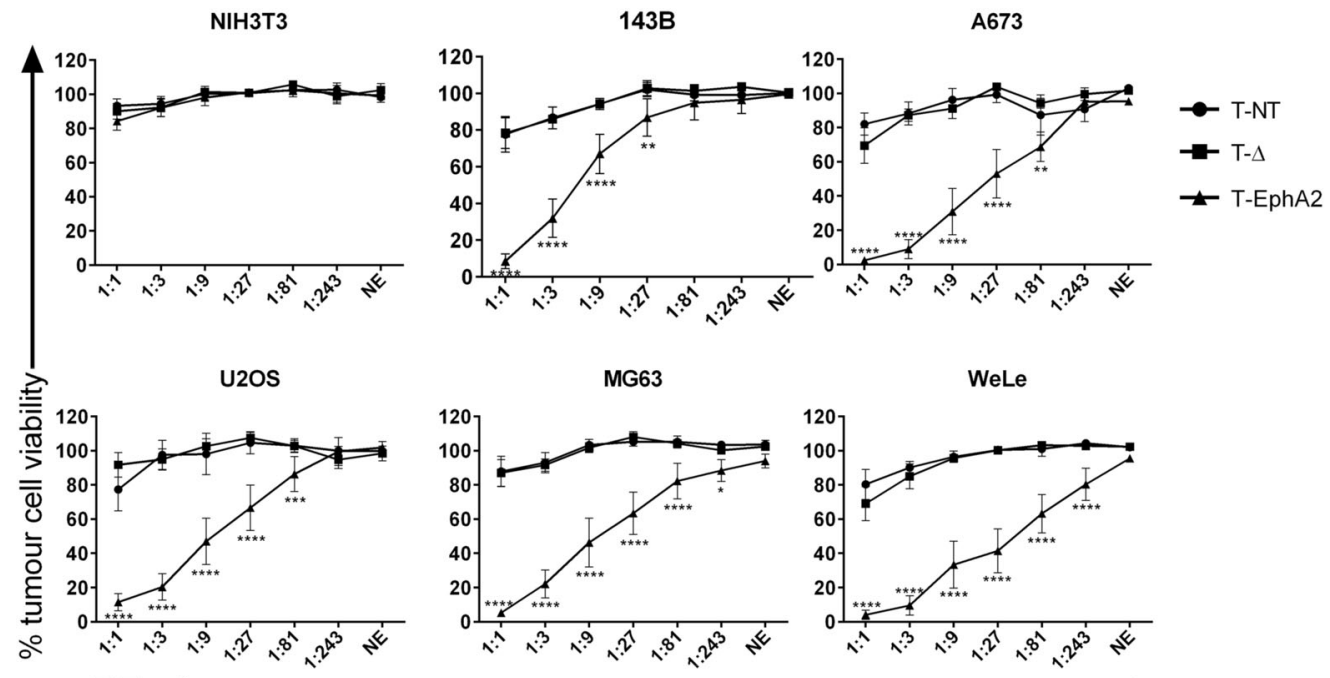

E:T ratio
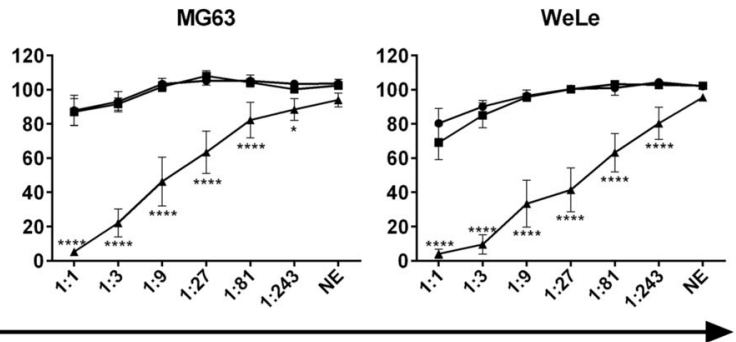

Fig. 3 In vitro assessment of anti-tumour activity of CAR T cells targeted against EphA2. Percentage (\%) Tumour cell viability $(Y$ axes), quantitated using a CellTiter-Glo 2.0 assay after $48 \mathrm{~h}$ of coculture with IL-15/IL-17 expanded nontransduced (T-NT) T cells, $\Delta$ CAR $(\mathrm{T}-\Delta)$ or EphA2-targeted CAR (T-EphA2) T cells at the indicated E:T ratios ( $X$ axes) in the absence of exogenous cytokines. At each point, percentage cell survival has been expressed relative to untreated tumour cells (set as $100 \%$ viability). NE no effector cell. The

ovary and placenta), digestive system tissues (appendix, stomach, colon, salivary gland and pancreas) and cardiovascular tissues (heart and lung).

\section{EphA2 expression on sarcoma cell lines}

All sarcoma cell lines tested by flow cytometry were positive for EphA2 protein expression when compared with a positive control neuroblastoma cell line (SHEP) and the negative control cell line TF-1 (Fig. 1c). OS Cell lines 143B, U2OS and MG63, ES lines A673 and ES8 and the murine fibroblast cell line NIH3T3 (as a negative control) were used for subsequent in vitro assays for EphA2 CAR T cell (T-EphA2) efficacy. Cell lines 143B and A673 were used in in vivo assays for EphA2 CAR T cell (T-EphA2) targeting.

\section{Generation of EphA2 CAR T cells using LV vector}

Gene transfer efficiencies for $\mathrm{CD} 3 / \mathrm{CD} 28$ activated $\mathrm{T}$ cells with either the EphA2CAR-tCD19 and EphA2CAR-tEGFR LV (Fig. 2a) ranged between 35 and $81 \%$ (tCD19 vector) and 5 and $62 \%$ (tEGFR vector). CAR T cells were further expanded for up to 10 days prior to use in experiments, typically with $\sim 500$-fold expansion. Control $\triangle$ CAR T cells (T- $\Delta)$ transduced with the $\Delta \mathrm{EphA} 2(\Delta)$ CAR constructs showed equivalent proportions of transduced cells. The positive tCD19 (Fig. 2b) or tEGFR (Fig. 2c) transduced negative control cell line NIH3T3 (top left) does not express EphA2. Data show the mean \pm SEM from independent CAR $T$ and control cell preparations generated from PBMC of four different donors (biological replicates). For each cell line, mean values at each E:T ratio were compared between T-EphA2 with either T-NT or T- $\Delta$ using a two-way ANOVA (with Tukey's multiple comparisons test) with statistically significant differences indicated: $* P<0.05, * * P<0.01$, $* * * P<0.001$, $* * * * P<0.0001$.

CAR T cells was used to determine CAR T cell doses for in vitro assay and in vivo delivery.

\section{EphA2 CAR T-cell activation and cytotoxicity against EphA2 expressing sarcoma cell lines in vitro}

Forty-eight hour incubation of EphA2 CAR T cells with 3 OS and 2 ES cell grown in monolayer culture caused significant $(P<0.01)$ cytotoxicity at E:T ratios of between $1: 1$ and 1:27 (Fig. 3). No cytotoxic effect was seen after coculture with nontransduced T cells (T-NT) or $\triangle$ CAR T cells (T- $\Delta$ ), or after co-culture of EphA2 CAR T (T-EphA2) cells with the EphA2 negative murine NIH3T3 cell line. This potent effect was seen across four independent donors. Quantitation of both IL-2 (Fig. 4a) and IFN- $\gamma$ (Fig. 4b) production by EphA2 CAR T cells, T-NT and T- $\Delta$ cells over the same range of E:T ratios, following co-culture with the same panel of tumour cell lines, showed significantly higher levels $(P<0.05)$ of cytokine secretion by EphA2 CAR $T$ cells over levels produced by control cells, indicative of antigen-specific tumour cell recognition by EphA2 CAR $T$ cells. These differences peaked at E:T ratios of 1:1 and 1:3 with detectable cytokine secretion diminishing as the number of CAR T cells relative to tumour cells declined. In addition, the xCelligence real-time cell analysis assays monitoring co-culture of T-EphA2 or control $\mathrm{T}$ cells with either the OS cell line 143B or the ES cell line A673 over the same time period similarly demonstrated that T-EphA2 
Fig. 4 In vitro production of IL-2 and IFN- $\gamma$ by EphA2targeted CAR $T$ cells. Nontransduced (T-NT) T cells, $\Delta$ CAR $(\mathrm{T}-\Delta)$ or EphA2 CAR (TEphA2) $T$ cells were cultured in the absence of exogenous cytokines in medium alone (medium), negative control cells (NIH3T3) or sarcoma cell lines at indicated E:T ratios ( $X$ axes). Supernatant collected after 48 hours was assayed for a IL-2 and $\mathbf{b}$ IFN $\gamma$ production, and quantitated by ELISA ( $Y$ axes). Data show the mean \pm SEM from four independent $\mathrm{T}$ cell donors (biological replicates). For each cytokine and cell line, results for two-way ANOVA comparisons between T-EphA2 with either T-NT or T- $\Delta$ conditions (with Tukey's multiple comparisons test) with statistically significant differences indicated: $* P<0.05$, $* * P<0.01, * * * P<0.001$ and $* * * * P<0.0001$.
IL - 2

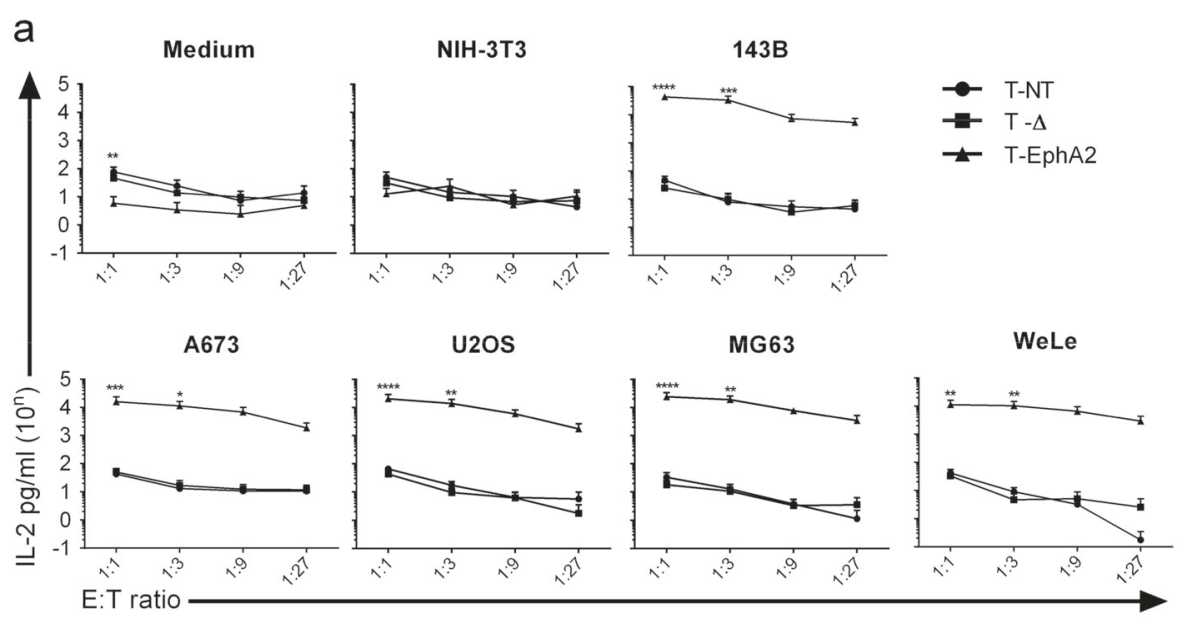

IFN $\gamma$

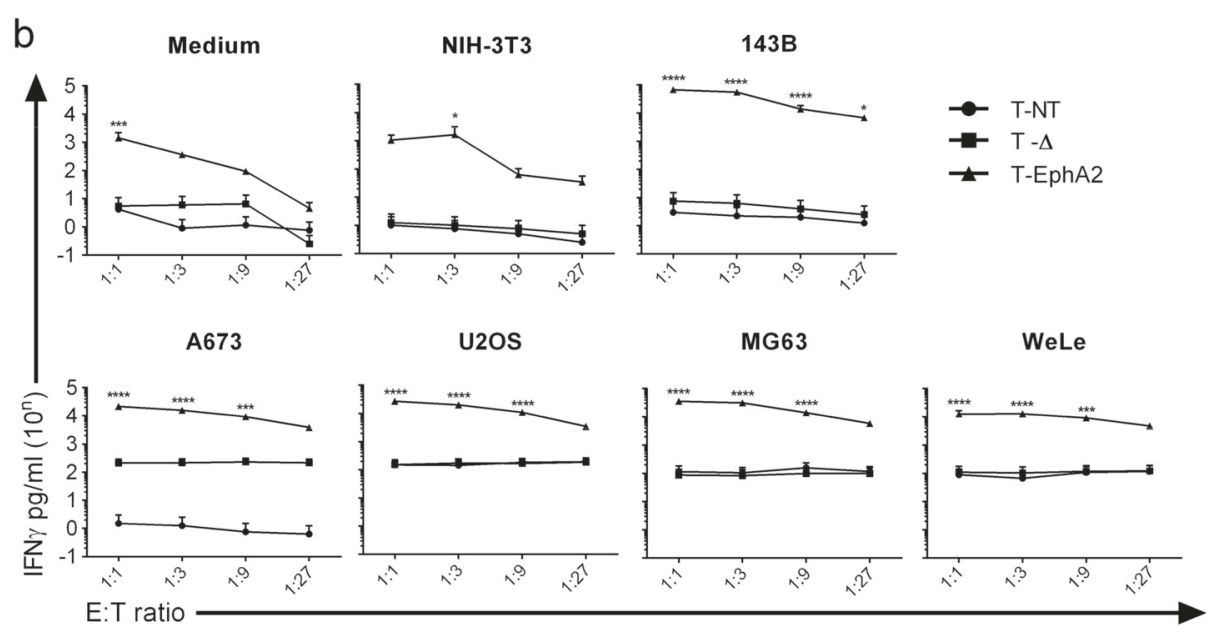

cells, but not T-NT or T- $\Delta$, were effective at killing tumour cells at E:T ratios of 1:1, 1:5 and 1:25 (Supplemental Fig. 2 ). This data is in line with previously reported potencies for EphA2 CAR $\mathrm{T}$ cells generated using gamma-retroviral constructs containing the same humanised EphA2 antibody sequence $[41,42]$ but targeting EphA $2^{+}$glioma cell lines. It demonstrates that constitutive expression of the EphA2 CAR molecule driven by the huEF1- $\alpha$ promoter can drive the required response to EphA2 expressing sarcoma cell lines to kill this tumour type at low E:T ratios, with effective and specific activation upon antigen engagement.

\section{EphA2 CAR T cell targeting of OS and ES cells in established tumours in vivo}

Two subcutaneous tumour cell models, one using the OS cell line 143B and the second using the ES cell line A673, were used to test the in vivo efficacy of Epha2 directed CAR T cells in NSG mice (Fig. 5). In both models, intratumoural (IT) injection of $5 \times 10^{6}$ EphA2 CAR $\mathrm{T}$ cells per tumour (T-EphA2) resulted in tumour regression and eradication (Fig. 5a), whereas in mice receiving treatment with $\Delta$ CAR T cells (T- $\Delta$ ), nontransduced $\mathrm{T}$ cells (T-NT) or vehicle (PBS), tumour growth continued in line with previously established kinetics, resulting in euthanasia of tumour bearing mice at a median of 21 days after tumour cell inoculation (Fig. 5a, b). Significant differences in size $(P<0.01)$ between regressing tumours in $\mathrm{T}$ EphA2 treated animals and growing tumours in control treated mice were first evident at 8 and 9 days following treatment in the OS and ES models respectively. Animals receiving this dose of T-EphA2 showed extended survival out to a mean of 74 days and 88 days in the OS and ES models respectively (Fig. $5 b$ ). IT delivery of lower doses of T-EphA2 cells $\left(5 \times 10^{5}\right.$ and $5 \times 10^{4}$ per tumour $)$ in the OS model did not have a significant effect on tumour growth (data not shown) and these doses were omitted from testing in the ES model. 

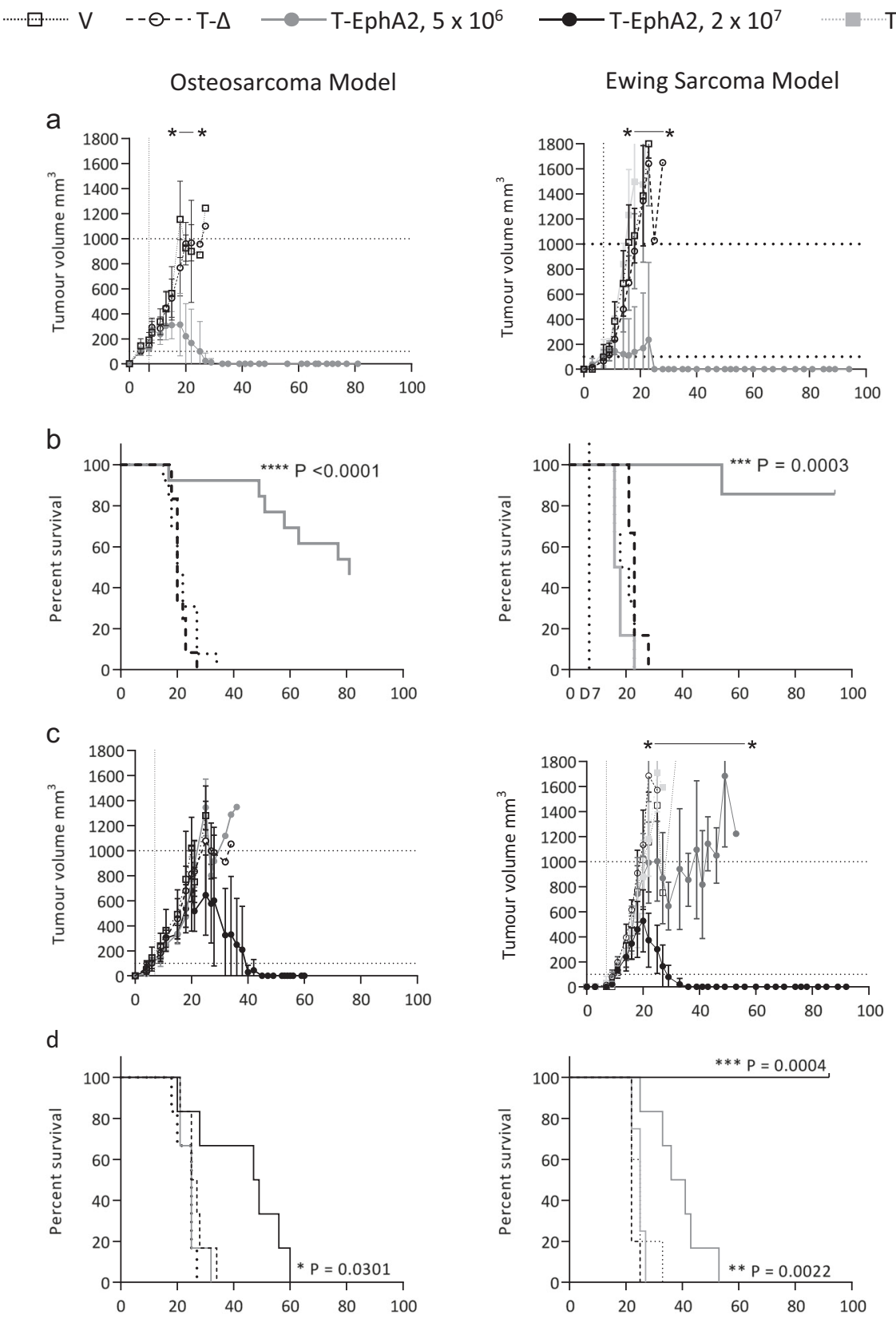

Days post inoculation of tumour cells

Fig. 5 Subcutaneous tumour growth and survival curves for OS and ES tumour-bearing mice. a Tumour growth curves (volume, $\mathrm{mm}^{3}$ over time) for subcutaneous OS tumours (left) and ES tumours (right) in mice receiving EphA2 CAR T cells (T-EphA2) or control treatments (PBS, T- $\Delta$, NT-T) intra-tumourally on Day 7 (dotted line). Mean \pm SD for each group of animals is shown, $n=12$ for the OS model and $n=6$ for the ES model. *_* indicates period over which significant differences in mean tumour volume between T-EphA2 and control treated tumours were seen (t-test with Holm-Sidak correction for multiple comparisons). b Kaplan Meier survival curves for OS (right) and ES (left) tumour bearing mice receiving EphA2 CAR $\mathrm{T}$ cells (T-EphA2) or control treatments (PBS, T- $\Delta, \mathrm{NT}-\mathrm{T}$ ) intratumourally. Statistical comparisons shown are between T-EphA2 and

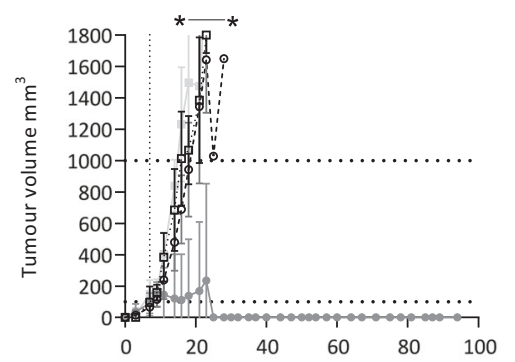

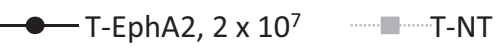

\section{Ewing Sarcoma Model}

-NT 


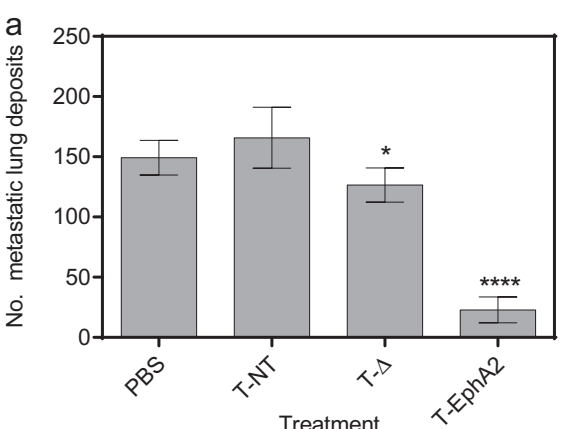

Fig. 6 EphA2 CAR T cells reduce metastatic osteosarcoma tumour burden in mice. a Mean Day 14 macroscopic counts of GFP-positive 143B metastases on the external surfaces of lungs of mice receiving EphA2 CAR T (T-EphA2) cells or control treatments (PBS, T- $\Delta$ or NT-T) on Day 7. b Mean Day 14 macroscopic counts of GFP ${ }^{+} 143 \mathrm{~B}$ metastases on the external surfaces of livers of mice receiving EphA2 CAR T (T-EphA2) cells or control treatments (PBS, T- $\Delta$ or NT-T) on

By contrast with IT delivery, intravenous (IV) injection of $5 \times 10^{6}$ EphA2 CAR $\mathrm{T}$ cells did not result in any significant tumour regression (Fig. 5c), nor extension of survival (Fig. 5d) in the OS model. In the ES model, this dose led to a short (39 day) delay in tumour volume reaching the experimental endpoint, but not tumour regression. However, IV administration of a higher dose of $2 \times 10^{7}$ cells/ mouse of T-EphA2 CAR $\mathrm{T}$ cells did result in tumour regression and extended survival (Fig. 5c, d) in both OS and ES models. Significant differences $(P<0.01)$ in tumour volume between T-EphA2 and control treatments was first seen in the ES model 15 days after treatment. In the OS model, all tumours regressed to become undetectable, however, due to the variability in tumour volume measured throughout this process, no statistical differences were seen between control and treated animals prior to control animals being euthanased. As for experiments testing IT delivery, in all animals receiving control treatments via IV delivery, tumours grew according to previously established kinetics resulting in euthanasia of animals at a median of 21 days following tumour inoculation.

Mice with tumours cleared by EphA2 CAR T cell (TEphA2) administration were held for a maximum of 100 days post injection, and a proportion of these developed histologically confirmed graft versus host disease (GVHD) from approximately day 50. Signs of GVHD included progressive weight loss, fur loss and eczema. This was treated by administration of topical steroids and antibiotics as directed by a veterinarian. Animals with GVHD were euthanased when necessary according to ethical guidelines, resulting in a decrease in surviving animal numbers after 50 days in the EphA2 CAR T treated group in the OS model (Fig. 5b, d). The occurrence of GVHD was donor dependent with all affected mice confined to experiments using $\mathrm{T}$ cells derived from one (of two) donors.

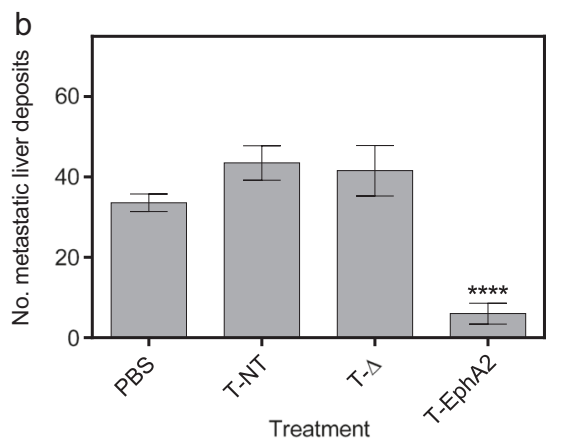

Day 7. Error bars indicate \pm SEM for two experiments using two independent donors for T cells, $n=9$ mice per group for donor 1 and $n=4$ mice per group for donor 2. Statistical comparisons shown indicate significant differences $(* P<0.05, * * * * P<0.0001$, Student's $t$ test) between mean values for treatment groups (T- $\Delta$ or T-EphA2) with the NT-T control.

Since animals that received control $\triangle \mathrm{CAR} T$ cells or nontransduced $\mathrm{T}$ cells were euthanased well before GVHD was seen in EphA2 CAR T treated animals, it is difficult to determine whether this side-effect of treatment was due to non-specific EphA2 CAR $\mathrm{T}$ activity, directed through antigen cross-reactivity, or due to more generalised human vs mouse reactivity. We did note some positive non-specific labelling for human EphA2 protein by IHC in mouse lung and liver sections (Supplemental Fig. 1), in contrast to the equivalent human tissues, indicating that EphA2 CAR T cell cross-reactivity was a possibility. Staining for EphA2 expression using the humanised EphA2 antibody used for generation of the EphA2 CAR in mouse tissues could elucidate the underlying mechanism for this side-effect and assist in refining future pre-clinical studies.

\section{EphA2 CAR T-cell efficacy against metastatic osteosarcoma cells in vivo}

GFP expressing 143B cells were used to establish disseminated metastatic disease in the livers and lungs of recipient female NSG mice for in vivo testing of efficacy of EphA2 directed CAR T cells (T-EphA2). In initial dose finding studies, I.V. delivery of $2.5 \times 10^{5} \mathrm{GFP}^{+} 143 \mathrm{~B}$ cells resulted in a substantial and reproducible metastatic burden in both the lungs and livers of animals when assessed 14-16 days following injection (Supplemental Fig. 3). In two experiments using independent donors, intravenous delivery of $5 \times 10^{6}$ EphA2 CAR T cells (T-EphA2)/mouse 7 days after tumour cell inoculation resulted in either an absence (donor 1T cells) of or a significant decrease (donor $2 \mathrm{~T}$ cells) in the number of visible metastatic nodules counted in both the lungs and livers of mice in comparison to animals receiving $\Delta$ CAR $\mathrm{T}$ cells $(\mathrm{T}-\Delta)$, nontransduced T cells (T-NT) or vehicle (PBS; Fig. 6). Although it was of 
a

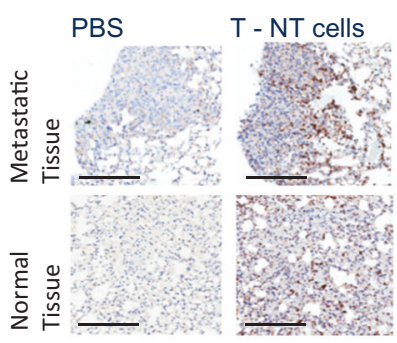

b

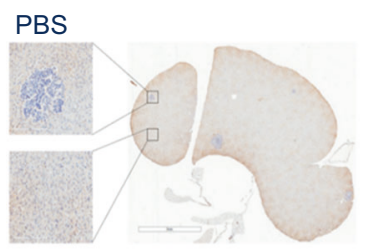

T- $\Delta$ cells

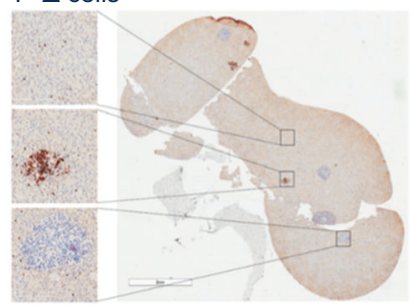

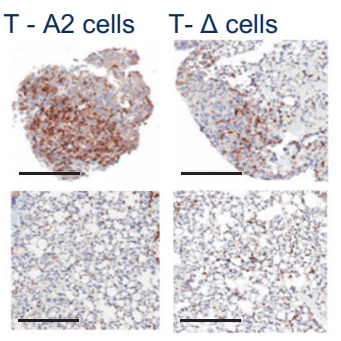

T - NT cells

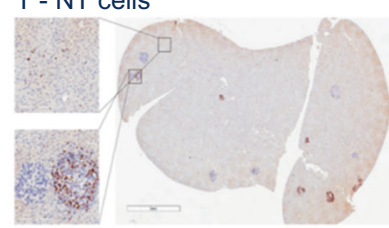

$\mathrm{T}-\mathrm{A} 2$ cells
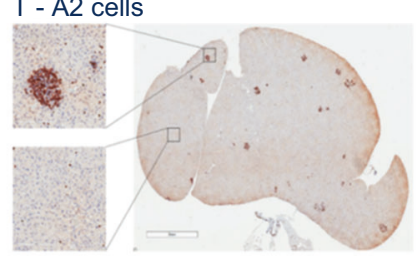

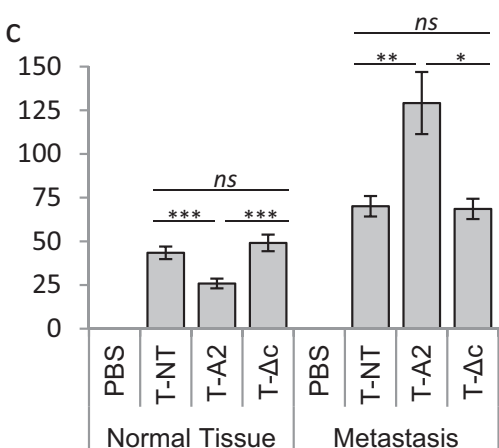

d

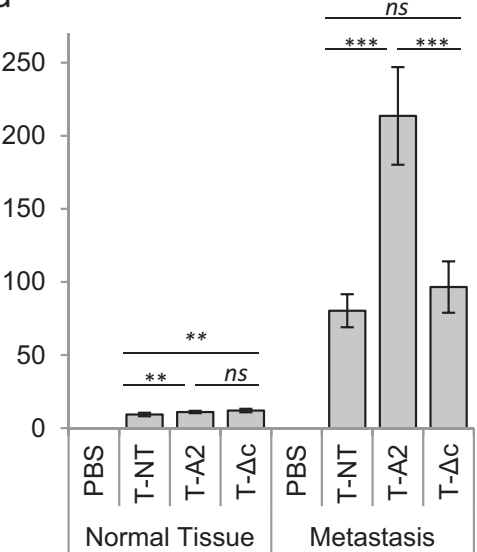

Fig. 7 CAR T cell infiltration into lungs and livers of NSG mice. a IHC staining for human CD3 in sections of lungs harvested at Day 14 from NSG mice treated with EphA2 CAR T (T-EphA2) cells or control treatments, PBS, nontransduced T cells (T-NT) and $\triangle \mathrm{CAR}$ cells (T- $\Delta$ ), on Day 7. Scale bar, $200 \mu \mathrm{m}$. Top row shows the extent of $\mathrm{T}$ cell infiltration close to metastatic OS deposits in lungs of mice and the bottom row shows $\mathrm{T}$ cell infiltration into surrounding normal tissue for each treatment group. b IHC staining for human CD3 in sections of livers harvested at Day 14 from NSG mice treated with EphA2 CAR T (T-EphA2) cells or control treatments, PBS, nontransduced T cells (TNT) and $\Delta$ CAR cells (T- $\Delta$ ), on Day 7. Scale bar, $5 \mu \mathrm{m}$. Top row shows the extent of $\mathrm{T}$ cell infiltration in livers of receiving PBS (left) or nontransduced (T-NT) control T cells (right), bottom row shows $\mathrm{T}$ cell

interest to test whether EphA2 CAR T-cell administration could prolong survival in this model, assessment of metastatic burden for all treatment groups was routinely performed between 7 and 9 days post treatment (14-16 days post tumour cell inoculation). The human 143B osteosarcoma cell line used in this model is highly efficient at seeding metastatic deposits in both the lungs and livers of recipient mice, and this end point was chosen to avoid animals succumbing to high disease burden unexpectedly, despite daily welfare monitoring.

\section{T-cell infiltration and density in livers and lungs with metastases}

Immunohistochemistry for human CD3 within sections of liver and the lungs of mice-bearing metastases provided direct evidence for the specificity of EphA2 CAR T-cell (T- infiltration into lungs of mice receiving $\Delta$ CAR T cells (T- $\Delta$ ) (left) or EphA2 CAR T cells (T-EphA2) (right). Enlarged images taken from were indicated in each section. c Quantitation of T-cell density in normal, non-metastatic lung tissue compared with metastatic deposits. d Quantitation of T-cell density in normal, non-metastatic liver tissue compared with metastatic deposits. For both $\mathbf{c}$ and $\mathbf{d}$, means are shown for counts (CD3 positive T cells over 3 high-power fields, $Y$ axis) performed on tissue harvested from six mice from each group. Error bars show \pm SD. Statistical comparisons shown indicate significant differences $(* * P<001$, $* * * P<0.001$, Student's $t$ test) between mean values for treatment groups as indicated by the bars, ns no significant difference.

EphA2) targeting EphA2 ${ }^{+}$OS cells and their capacity to traffic to disseminated tumour deposits in vivo. In both lung and liver sections, $\mathrm{T}$-cell density was highest in tissues close to metastatic tumour deposits in mice receiving EphA2 CAR $\mathrm{T}$ cells when compared with those receiving either nontransduced $\mathrm{T}$ cells (T-NT) or $\Delta$ CAR $\mathrm{T}$ cells (T- $\Delta$; Fig. 7). In the lungs, EphA2 CAR T cells were preferentially observed to be clustered around metastatic tumour deposits, and depleted in number across areas of normal tissue (Fig. 7a, b). In the liver (Fig. 7c, d), CD3 + T cells were observed both in association with, and not associated with metastatic deposits in mice-receiving nontransduced (T-NT) and $\Delta$ CAR T cells (T- $\Delta)$. By contrast, in mice receiving EphA2 CAR T cells (T-EphA2), $\mathrm{CD}^{+}{ }^{+} \mathrm{T}$ cells were significantly associated with metastatic tumours, at high density. In the liver, the density of $\mathrm{T}$ cells in non-metastatic, normal regions of the tissue was low. For one of two CAR T cell 
donors used in this study, for which residual metastases were counted at Day 14, staining of liver and lung sections for EphA2 expression indicated that a proportion of residual metastatic cells were negative, or below the level of detection for IHC EphA2 staining (Supplemental Fig. 4). However, EphA2 ${ }^{+}$residual tumour cells were also observed, indicating that for this donor, with apparently lower potency CAR $\mathrm{T}$ cells, an increased dose, or an alternative dosing schedule may have been necessary to completely eradicate established $\mathrm{EphA} 2^{+}$metastatic disease.

\section{Discussion}

While CAR T-cell therapy has been a highly effective immune therapy for leukaemia, the treatment remains to be translated effectively into the solid tumour context. Our work demonstrates that EphA2 directed CAR T cells can effectively kill EphA2 expressing OS and ES tumour cells in preestablished, localised xenografts in immune deficient mice, associated with prolonged survival. In addition, EphA2 CAR T cells caused a significant reduction or elimination of tumour burden in a mouse model of disseminated OS metastases. In the subcutaneous models of localised tumours, the effect was dose and route of delivery dependent, with localised delivery requiring a lower dose than systemic delivery, pointing to a need to carefully consider the route of delivery to these tumour types in patients. In the metastatic OS model, however, EphA2 CAR T-cells delivered systemically were capable of migrating into and disseminating throughout murine lung and liver to effectively target metastatic tumour deposits. Although nontransduced (T-NT) and $\Delta$ CAR (T- $\Delta$ ) T cells were also observed within these tissues, no reduction in the numbers of metastatic nodules was observed in animals receiving these control $\mathrm{T}$-cell preparations. Our metastatic model outcomes also highlighted variation in EphA2 CAR Tcell effect in preparations derived from different donors, providing evidence that donor-specific factors will materially affect CAR T-cell efficacy when this methodology is translated into the clinic. Compounding this variability, which may relate to both intrinsic differences between donors, or extrinsic factors such as PBMC harvesting and/or CAR T-cell manufacturing culture and transduction conditions will be the heterogeneity of EphA2 antigen expression within tumours. In our metastatic OS model, EphA2 negative tumour cell deposits were evident among those remaining after EphA2 CAR treatment, supporting predictions from the field that antigen down-regulation or absence within tumours will likely require administration of multivalent $\mathrm{CARs}$ or combinatorial approaches using CARs to alternative TAAs.

As with other TAAs expressed in solid tumours, this study identified variability between patients in relation to EphA2 expression (weak to strong) in addition to patients where no EphA2 expression was observed. Although almost half of the OS patient samples in our cohort expressed EphA2, only a minor percentage of ES tumours did so. In contrast with other TAAs being targeted for solid tumours that show some level of normal tissue distribution [10], importantly, our data shows that EphA2 protein expression is absent across a broad range of normal tissues. The results of recently completed and ongoing early phase clinical trials targeting EphA2 expressing gliomas will provide safety data regarding EphA2 as a clinically applicable TAA for sarcoma. Our tEGFR EphA2 CAR construct is designed to be targetable by Cetuximab (Erbitux) [49], an inhibitor of epidermal growth factor receptor (EGFR), to provide a mechanism by which offtumour, but on-target toxic effects can be mitigated.

Recurrent bone sarcomas of childhood are low survival malignancies, and new therapies for these patients are needed to bring about the improvements in survival seen in other types of childhood cancers over the past decades. Our study provides pre-clinical evidence that EphA2 is a valuable target for the development of CAR T-cell therapies for sarcomas, adding another antigen to a growing list that will be needed to comprehensively cover this heterogeneous group of solid tumours. Alongside our demonstration of specificity and a capacity for EphA2 CAR T cells to find their target in tissues harbouring metastatic sarcoma tumour cells, we could find no evidence for antigen expression that would predict for significant off tumour effects. In agreement with studies in brain tumour models, our data shows superior efficacy when the CAR T cells are delivered locally to the tumour, underlining the need for consideration of delivery route for the design of early phase clinical trial protocols for safety testing. Further work focussing on combinatorial testing of EphA2 CAR $\mathrm{T}$ cells with CAR $\mathrm{T}$ cells targeting alternative antigens, with immune checkpoint blockade and with current conventional chemotherapy agents will elucidate a way forward in designing an effective CAR T-cell therapy for osteosarcoma and Ewing sarcoma.

Acknowledgements The authors gratefully acknowledge the provision of tumour TMA's from the Sydney Children's Tumour Bank Network (SCHNTBN).

Funding This work was funded by project grants received from The Kid's Cancer Project (TKCP), Cancer Institute NSW through The Kid's Cancer Alliance (KCA) and The Australian and New Zealand Sarcoma Association (ANZSA).

\section{Compliance with ethical standards}

Conflict of interest The authors declare that they have no conflict of interest.

Publisher's note Springer Nature remains neutral with regard to jurisdictional claims in published maps and institutional affiliations. 


\section{References}

1. Maude SL, Laetsch TW, Buechner J, Rives S, Boyer M, Bittencourt $\mathrm{H}$, et al. Tisagenlecleucel in children and young adults with B-cell lymphoblastic leukemia. New Engl J Med. 2018;378:439-48.

2. Trieb K, Lechleitner T, Lang S, Windhager R, Kotz R, Dirnhofer S. Evaluation of HLA-DR expression and T-lymphocyte infiltration in osteosarcoma. Pathol Res Pract. 1998;194:679-84.

3. Machado I, López-Guerrero JA, Scotlandi K, Picci P, LlombartBosch A. Immunohistochemical analysis and prognostic significance of PD-L1, PD-1, and CD8+ tumor-infiltrating lymphocytes in Ewing's sarcoma family of tumors (ESFT). Virchows Arch. 2018;472:815-24.

4. Fritzsching B, Fellenberg J, Moskovszky L, Sápi Z, Krenacs T, Machado I, et al. CD8+/FOXP3+-ratio in osteosarcoma microenvironment separates survivors from non-survivors: a multicenter validated retrospective study. Oncoimmunology. 2015;4:e990800.

5. Théoleyre S, Mori K, Cherrier B, Passuti N, Gouin F, Rédini F, et al. Phenotypic and functional analysis of lymphocytes infiltrating osteolytic tumors: use as a possible therapeutic approach of osteosarcoma. BMC Cancer. 2005;5:123.

6. Rivoltini L, Arienti F, Orazi A, Cefalo G, Gasparini M, Gambacorti-Passerini C, et al. Phenotypic and functional analysis of lymphocytes infiltrating paediatric tumours, with a characterization of the tumour phenotype. Cancer Immunol Immunother. 1992;34:241-51.

7. Ahmed N, Salsman VS, Yvon E, Louis CU, Perlaky L, Wels WS, et al. Immunotherapy for osteosarcoma: genetic modification of $\mathrm{T}$ cells overcomes low levels of tumor antigen expression. Mol Ther. 2009;17:1779-87.

8. Ahmed N, Brawley VS, Hegde M, Robertson C, Ghazi A, Gerken C, et al. Human Epidermal Growth Factor Receptor 2 (HER2) -specific chimeric antigen receptor-modified $\mathrm{T}$ cells for the immunotherapy of HER2-positive sarcoma. J Clin Oncol. 2015;33:1688-96.

9. Kailayangiri S, Altvater B, Meltzer J, Pscherer S, Luecke A, Dierkes $\mathrm{C}$, et al. The ganglioside antigen GD2 is surfaceexpressed in Ewing sarcoma and allows for MHC-independent immune targeting. Br J Cancer. 2012;106:1123-33.

10. Huang X, Park H, Greene J, Pao J, Mulvey E, Zhou SX, et al. IGF1R- and ROR1-specific CAR T cells as a potential therapy for high risk sarcomas. PLoS ONE. 2015;10:e0133152.

11. Krenciute G, Krebs S, Torres D, Wu M-F, Liu H, Dotti G, et al. Characterization and functional analysis of $\mathrm{scFv}$-based chimeric antigen receptors to redirect T cells to IL13R $\alpha 2$-positive glioma. Mol Ther. 2016;24:354-63.

12. Zou C, Shen J, Tang Q, Yang Z, Yin J, Li Z, et al. Cancer-testis antigens expressed in osteosarcoma identified by gene microarray correlate with a poor patient prognosis. Cancer. 2012;118:1845-55.

13. Flanagan JG, Vanderhaeghen P. The ephrins and Eph receptors in neural development. Annu Rev Neurosci. 1998;21:309-45.

14. Lindberg RA, Hunter T. cDNA cloning and characterization of eck, an epithelial cell receptor protein-tyrosine kinase in the eph/elk family of protein kinases. Mol Cell Biol. 1990;10:6316-24.

15. Kang BH, Jensen KJ, Hatch JA, Janes KA. Simultaneous profiling of 194 distinct receptor transcripts in human cells. Sci Signal. 2013;6:rs13.

16. Pasquale EB. Eph receptors and ephrins in cancer: bidirectional signalling and beyond. Nat Rev Cancer. 2010;10:165-80.

17. Wykosky J, Debinski W. The EphA2 receptor and ephrinA1 ligand in solid tumors: function and therapeutic targeting. Mol Cancer Res. 2008;6:1795-806.
18. Tandon M, Vemula SV, Mittal SK. Emerging strategies for EphA2 receptor targeting for cancer therapeutics. Expert Opin Ther Targets. 2011;15:31-51.

19. Incerti M, Russo S, Callegari D, Pala D, Giorgio C, Zanotti I, et al. Metadynamics for perspective drug design: computationally driven synthesis of new protein-protein interaction inhibitors targeting the EphA2 receptor. J Med Chem. 2017;60:787-96.

20. Fritsche-Guenther R, Noske A, Ungethüm U, Kuban R-J, Schlag $\mathrm{PM}$, Tunn P-U, et al. De novo expression of EphA2 in osteosarcoma modulates activation of the mitogenic signalling pathway. Histopathology. 2010;57:836-50.

21. Sáinz-Jaspeado M, Huertas-Martinez J, Lagares-Tena L, Martin Liberal J, Mateo-Lozano S, de Alava E, et al. EphA2-induced angiogenesis in ewing sarcoma cells works through bFGF production and is dependent on caveolin-1. PLoS ONE. 2013;8: e71449.

22. Garcia-Monclús S, López-Alemany R, Almacellas-Rabaiget $\mathrm{O}$, Herrero-Martín D, Huertas-Martinez J, Lagares-Tena L, et al. EphA2 receptor is a key player in the metastatic onset of Ewing sarcoma. Int J Cancer. 2018;143:1188-201.

23. Dunne PD, Dasgupta S, Blayney JK, McArt DG, Redmond KL, Weir J-A, et al. EphA2 expression is a key driver of migration and invasion and a poor prognostic marker in colorectal cancer. Clin Cancer Res. 2016;22:230-42.

24. Zelinski DP, Zantek ND, Stewart JC, Irizarry AR, Kinch MS. EphA2 overexpression causes tumorigenesis of mammary epithelial cells. Cancer Res. 2001;61:2301-6.

25. Duxbury MS, Ito H, Zinner MJ, Ashley SW, Whang EE. EphA2: a determinant of malignant cellular behavior and a potential therapeutic target in pancreatic adenocarcinoma. Oncogene. 2004;23:1448-56.

26. Parri M, Taddei ML, Bianchini F, Calorini L, Chiarugi P. EphA2 reexpression prompts invasion of melanoma cells shifting from mesenchymal to amoeboid-like motility style. Cancer Res. 2009;69:2072-81.

27. Brannan JM, Sen B, Saigal B, Prudkin L. EphA2 in the early pathogenesis and progression of non-small cell lung cancer. Cancer Prev. 2009;2:1039-49.

28. Kinch MS, Moore M-B, Harpole DH Jr. Predictive value of the EphA2 receptor tyrosine kinase in lung cancer recurrence and survival. Clin Cancer Res. 2003;9:613-8.

29. Herrem CJ, Tatsumi T, Olson KS, Shirai K, Finke JH, Bukowski $\mathrm{RM}$, et al. Expression of EphA2 is prognostic of disease-free interval and overall survival in surgically treated patients with renal cell carcinoma. Clin Cancer Res. 2005;11:226-31.

30. Thaker PH, Deavers M, Celestino J, Thornton A, Fletcher MS, Landen $\mathrm{CN}$, et al. EphA2 expression is associated with aggressive features in ovarian carcinoma. Clin Cancer Res. 2004;10:5145-50.

31. Wang L-F, Fokas E, Bieker M, Rose F, Rexin P, Zhu Y, et al. Increased expression of EphA2 correlates with adverse outcome in primary and recurrent glioblastoma multiforme patients. Oncol Rep. 2008;19:151-6.

32. Posthumadeboer J, Piersma SR, Pham TV, van Egmond PW, Knol JC, Cleton-Jansen AM, et al. Surface proteomic analysis of osteosarcoma identifies EPHA2 as receptor for targeted drug delivery. Br J Cancer. 2013;109:2142-54.

33. Coffman KT, Hu M, Carles-Kinch K, Tice D, Donacki N, Munyon K, et al. Differential EphA2 epitope display on normal versus malignant cells. Cancer Res. 2003;63:7907-12.

34. Jackson D, Gooya J, Mao S, Kinneer K, Xu L. A human antibody-drug conjugate targeting EphA2 inhibits tumor growth in vivo. Cancer Res. 2008;68:9367-74.

35. Lee J-W, Han HD, Shahzad MMK, Kim SW, Mangala LS, Nick $\mathrm{AM}$, et al. EphA2 immunoconjugate as molecularly targeted 
chemotherapy for ovarian carcinoma. J Natl Cancer Inst. 2009;101:1193-205.

36. Annunziata CM, Kohn EC, LoRusso P, Houston ND, Coleman RL, Buzoianu M, et al. Phase 1, open-label study of MEDI-547 in patients with relapsed or refractory solid tumors. Invest New Drugs. 2013;31:77-84.

37. Alves PMS, Faure O, Graff-Dubois S, Gross DA. EphA2 as target of anticancer immunotherapy: identification of HLA-A* 0201restricted epitopes. Cancer Res. 2003;63:8476-80.

38. Pollack IF, Jakacki RI, Butterfield LH, Hamilton RL, Panigrahy A, Normolle DP, et al. Immune responses and outcome after vaccination with glioma-associated antigen peptides and polyICLC in a pilot study for pediatric recurrent low-grade gliomas. Neuro Oncol. 2016;18:1157-68.

39. Wesa AK, Herrem CJ, Mandic M, Taylor JL, Vasquez C, Kawabe $\mathrm{M}$, et al. Enhancement in specific CD8+ T cell recognition of EphA2+ tumors in vitro and in vivo after treatment with ligand agonists. J Immunol. 2008;181:7721-7.

40. Shi H, Yu F, Mao Y, Ju Q, Wu Y, Bai W, et al. EphA2 chimeric antigen receptor-modified $\mathrm{T}$ cells for the immunotherapy of esophageal squamous cell carcinoma. $J$ Thorac Dis. 2018;10:2779-88.

41. Li N, Liu S, Sun M, Chen W, Xu X, Zeng Z, et al. Chimeric antigen receptor-modified $\mathrm{T}$ cells redirected to EphA2 for the immunotherapy of non-small cell lung cancer. Transl Oncol. 2018;11:11-17.

42. Chow KK, Naik S, Kakarla S, Brawley VS, Shaffer DR, Yi Z, et al. $T$ cells redirected to EphA2 for the immunotherapy of glioblastoma. Mol Ther. 2013;21:629-37.
43. Yi Z, Prinzing BL, Cao F, Gottschalk S, Krenciute G. Optimizing EphA2-CAR T cells for the adoptive immunotherapy of glioma. Mol Ther Methods Clin Dev. 2018;9:70-80.

44. Donovan LK, Delaidelli A, Joseph SK, Bielamowicz K, Kristen Fousek K, Holgado BL et al. Locoregional delivery of CAR $\mathrm{T}$ cells to the cerebrospinal fluid for treatment of metastatic medulloblastoma and ependymoma. Nat Med. 2020; https://doi. org/10.1038/s41591-020-0827-2

45. Puttick S, Stringer BW, Day BW, Bruce ZC, Ensbey KS, Mardon $\mathrm{K}$, et al. EphA2 as a diagnostic imaging target in glioblastoma: a positron emission tomography/magnetic resonance imaging study. Mol Imaging. 2015;14:385-99.

46. Saletta F, Vilain RE, Gupta AK, Nagabushan S, Yuksel A, Catchpoole D et al. Programmed death-ligand 1 expression in a large cohort of pediatric patients with solid tumor and association with clinicopathologic features in neuroblastoma. JCO Precis Oncol. 2017;1:1-12.

47. Damschroder MM, Widjaja L, Gill PS, Krasnoperov V, Jiang W, Dall'Acqua WF, et al. Framework shuffling of antibodies to reduce immunogenicity and manipulate functional and biophysical properties. Mol Immunol. 2007;44:3049-60.

48. Wang X, Chang W-C, Wong CW, Colcher D, Sherman M, Ostberg JR, et al. A transgene-encoded cell surface polypeptide for selection, in vivo tracking, and ablation of engineered cells. Blood. 2011;118:1255-63.

49. Paszkiewicz PJ, Fräßle SP, Srivastava S, Sommermeyer D, Hudecek M, Drexler I, et al. Targeted antibody-mediated depletion of murine CD19 CAR T cells permanently reverses B cell aplasia. J Clin Invest. 2016;126:4262-72. 